\title{
GAMBARAN IKLIM LINGKUNGAN KERJA DI HOME INDUSTRY PEMBUATAN SANDAL RW 04 KELURAHAN PAMOYANAN KECAMATAN BOGOR SELATAN KOTA BOGOR TAHUN 2019
}

\author{
Faiz Rizki Afriza ${ }^{1)}$, Andi Asnifatima ${ }^{2)}$, Rahma Listyandini ${ }^{3)}$
}

\author{
${ }^{1)}$ Konsentrasi Kesehatan dan Keselamatan Kerja, Program Studi Kesehatan Masyarakat, Fakultas Ilmu Kesehatan \\ Universitas Ibn Khaldun Bogor \\ Email: faizrizki_afriza@yahoo.com \\ ${ }^{2}$ Program Studi Kesehatan Masyarakat, Fakultas Ilmu Kesehatan Universitas Ibn Khaldun Bogor \\ Email: asni@uika-bogor.ac.id \\ ${ }^{3)}$ Program Studi Kesehatan Masyarakat, Fakultas Ilmu Kesehatan Universitas Ibn Khaldun Bogor \\ Email: rahmalistyandini@uika-bogor.ac.id
}

\begin{abstract}
Abstrak
Iklim kerja adalah hasil perpaduan antara suhu, kelembaban, kecepatan gerakan udara dan panas radiasi dengan tingkat pengeluaran panas dari tubuh tenaga kerja sebagai akibat pekerjaannya. Tujuan dari penelitian ini untuk mengetahui Gambaran Iklim Lingkungan Kerja di Home Industry Pembuatan Sandal RW 04 Keluraan Pamoyanan Kecamatan Bogor Selatan Kota Bogor Tahun 2019. Jenis penelitian yang digunakan adalah jenis penelitian kuantitatif dengan desain analisis deskriptif. Teknik pengambilan sampel dilakukan dengan cara Total Sampling dengan responden sebanyak 69 orang pekerja yang bekerja di Home Industry pembuatan sandal RW 04. Pengambilan data menggunakan lembar pengukuran dan alat Wet Bulb Globe Temperature. Analisis penelitian ini menggunakan analisis univariat. Hasil pengukuran iklim lingkungan kerja ISBB (Indeks Suhu Basah dan Bola) didapatkan hasil rata-rata yaitu $29,93{ }^{\circ} \mathrm{C}$. Laju metabolik didapatkan bahwa mayoritas pekerja laju metaboliknya ringan sebanyak (65.2\%). Durasi kerja didapatkan bahwa mayoritas pekerja durasi kerjanya melebihi 8 jam dan istirahat hanya 30 menit $(75-100 \%)$ sebanyak (66.7\%). Jenis pakaian kerja didapatkan bahwa seluruh responden menggunakan pakaian kerja biasa sebesar $100 \%$. Kesimpulan dari penelitian ini adalah Hasil pengukuran iklim lingkungan kerja ISBB (Indeks Suhu Basah dan Bola) dengan menggunakan alat WBGT (Wet Bulb Globe Temperature) didapatkan hasil rata-rata yaitu $29,93{ }^{\circ} \mathrm{C}$ sedangkan pengukuran ISBB (Indeks Suhu Basah dan Bola) paling rendah $25,93^{\circ} \mathrm{C}$ dan hasil ISBB (Indeks Suhu Basah dan Bola) paling tinggi sebesar $33,22{ }^{\circ} \mathrm{C}$. Disarankan kepada pemilik Home Industry harus menyediakan satu ruangan khusus untuk produksi pembuatan sandal dengan ventilasi yang memenuhi standar sesuai dengan luas ruangan tersebut.
\end{abstract}

\section{Kata Kunci : Iklim Lingkungan Kerja, Laju Metabolik, Durasi Kerja dan Pakaian Kerja}

\section{Pendahuluan}

Menurut Komisi Gabungan ILO/WHO pada tahun 1950 dalam Kurniawidjaja (2010), kesehatan kerja adalah upaya mempertahankan dan meningkatkan derajat kesehatan fisik, mental dan kesejahteraan sosial semua pekerja yang setinggi-tinginya. Fokus utama dari Kesehatan Kerja adalah untuk mencapai pemeliharaan dan 
peningkatan derajat kesehatan pekerja dan kapasitas kerjanya, perbaikan kondisi lingkungan kerja dan pekerjaan yang kondusif bagi keselamatan dan kesehatan kerja, pengembangan pengorganisasian pekerjaan dan budaya kerja ke arah yang mendukung keselamatan dan kesehatan kerja dan meningkatkan kondisi soisal yang positif dan operasi yang lancar dan dapat meningkatkan produktivitas.

Iklim kerja adalah hasil perpaduan antara suhu, kelembaban, kecepatan gerakan udara dan panas radiasi dengan tingkat pengeluaran panas dari tubuh tenaga kerja sebagai akibat pekerjaannya, yang dimaksudkan dalam peraturan ini adalah iklim kerja panas (PER.13/MEN/X/2011). Kondisi temperatur lingkungan kerja yang ekstrim meliputi panas dan dingin yang berada di luar batas standar kesehatan dapat menyebabkan meningkatnya pengeluaran cairan tubuh melalui keringat sehingga bisa terjadi dehidrasi dan gangguan kesehatan lainnya yang lebih berat. Persoalan tentang bagaimana menentukan bahwa kondisi temperatur lingkungan adalah ekstrim menjadi penting, mengingat kemampuan manusia untuk beradaptasi sangat bervariasi dan dipengaruhi oleh banyak faktor. Namun demikian secara umum kita dapat menentukan batas kemampuan manusia untuk beradaptasi dengan temperatur lingkungan pada kondisi yang ekstrim dengan menentukan rentang toleransi terhadap temperatur lingkungan (Suma'mur, 2009).

Negara maju seperti Amerika Serikat, menyatakan bahwa penyakit akibat kerja terbesar yang sering ditemukan disebabkan oleh faktor kimia (bahan-bahan kimia). Selain faktor bahan-bahan kimia yang merupakan kelompok terbesar pertama di lingkungan kerja, maka faktor fisik adalah kelompok terbesar kedua dan menjadi sumber masalah penting lainnya. Salah satu faktor fisik adalah iklim kerja yang panas
(Soeripto, 2008). Tekanan panas mengenai tubuh manusia dapat mengakibatkan berbagai permasalahan kesehatan hingga kematian. Pada musim panas tahun 1995, 100 penduduk Chicago meninggal karena gelombang panas. Penelitian lain di Amerika menunjukan terjadi 400 kematian setiap tahun yang diakibatkan oleh tekanan panas. Di Jepang dari tahun 2001-2003 dilaporkan 483 orang tidak masuk kerja selama lebih dari 4 (empat) hari karena penyakit akibat panas dan 63 orang diantaranya meninggal.

Kondisi panas sekeliling yang berlebihan akan mengakibatkan rasa letih dan kantuk, mengurangi kestabilan dan meningkatkan jumlah angka kesalahan kerja (Nurmianto, 2003). Berdasarkan penelitian Krisanti, (2011) hasil pengukuran tekanan panas dibagian produksi CV Rakabu Furniture Surakarta melebihi NAB $\left(<28,0^{\circ} \mathrm{C}\right)$, di dapatkan tekanan panas raa-rata adalah $31,24^{\circ} \mathrm{C}$ dengan WBGT in minimal $28,4^{\circ} \mathrm{C}$ dan WBGT in maksimal $33,7^{\circ} \mathrm{C}$

Bengkel sandal adalah merupakan industry informal (Home Industri) pada umumnya dilaksanakan disekitar rumah dan umumnya adalah industry keluarga. Industry tersebut merupakan salah satu industry yang mempunyai risiko iklim kerja yang panas terhadap tenaga kerja, karena lingkungan tempat kerja yang menyatu dengan rumah serta kurangnya fentilasi diarea bengkel kerja (Telan, 2012). Gambaran tentang lingkungan bengkel sandal yang ada di RW 04 Kelurahan Pamoyanan Kecamatan Bogor Selatan Kota Bogor cenderung panas karena tempat produksi yang lebih tertutup mengakibatkan kurangnya udara masuk dalam ruangan.

Berdasarkan uraian diatas maka penulis akan melakukan penelitian mengenai Gambaran Iklim Lingkungan Kerja di Home Industry RW 04 Kelurahan Pamoyanan Kecamatan Bogor Selatan Kota Bogor Tahun 2019. 


\section{Metode}

Jenis penelitian yang akan digunakan adalah jenis penelitian kuantitatif. Penelitian kuantitatif merupakan penelitian dengan memperoleh data yang berbentuk angka atau data kualitatif yang diangkakan (Sugiyono, 2010). Dengan metode pengumpulan data menggunakan Analisis Deskriptif. Yang dimaksud dengan metode pengumpulan data Analisis Deskriptif adalah untuk menjelaskan/mendeskriptifkan karakteristik masing-masing variabel yang diteliti dan untuk meringkas kumpulan data hasil pengukuran sedemikian rupa sehingga kumpulan data tersebut berubah menjadi informasi yang berguna (Hastono, 2016)

Pengambilan data pada penelitian ini dilakukan di home industry bengkel sandal RW 04 Kelurahan Pamoyanan Kecamatan Bogor Selatan Kota Bogor Tahun 2019. Penelitian ini dilakukan mulai januari 2019.

Populasi dalam penelitian ini adalah seluruh bengkel sandal yang aktif dan pekerja di Home Industy RW 04 Kelurahan Pamoyanan Kecamatan Bogor Selatan Kota Bogor dengan jumlah 25 bengkel sandal dan

\section{Hasil}

Data yang digunakan dalam penelitian ini ialah data primer. Data primer dilakukan menggunakan lembar pengukuran dan pengukuran langsung menggunakan alat WBGT (Wet Bulb Globe Temperature) sebelum observasi responden kami meminta
69 Orang pekerja.

Sampel yang diambil dalam penelitian ini adalah 25 Home Industry pembuatan sandal yang aktif dan 69 pekerja. Bengkel sandal yang aktif adalah bengkel sandal yang produksi setiap hari kecuali hari minggu dan bengkel sandal yang tidak aktif adalah bengkel sandal yang produksi sandal hanya pada saat ada pesanan saja. Pengambilan sampel dilakukan dengan cara Total Sampling/Sampling Jenuh. Sampling jenuh/total sampling adalah Teknik Penentuan sampel bila semua anggota populasi digunakan sebagai sampel.

Menurut Sugiyono (2010) Variabel penelitian adalah suatu atribut atau sifat atau nilai dari orang, obyek atau kegiatan yang mempunyai variasi tertentu yang ditetapkan oleh peneliti untuk dipelajari dan kemudian ditarik kesimpulannya. Variabel dari penelitian ini adalah iklim lingkungan kerja, laju metabolik dan karakteristik pekerja di Home Industry RW 04 Kelurahan Pamoyanan Kecamatan Bogor Selatan Kota Bogor.

izin untuk mengambil data di Home Industry RW 04. Setelah meminta izin lalu segera melakukan pengukuran menggunakan lembar pengukuran dan alat WBGT (Wet Bulb Globe Temperature)

Tabel 1. Distribusi Frekuensi Hasil Pengukuran Laju Metabolik Pada Pekerja Yang Bekerja Di Home Industry Pembuatan Sandal RW 04 Kelurahan Pamoyanan Kecamatan Bogor Selatan Kota Bogor Tahun 2019

\begin{tabular}{llr|r|r|r} 
& \multicolumn{2}{c}{ Frequency } & Percent & Valid Percent & Cumulative Percent \\
\hline Valid & Ringan & 45 & 65.2 & 65.2 & 65.2 \\
\cline { 2 - 5 } & Sedang & 24 & 34.8 & 34.8 & 100.0 \\
\hline Total & 69 & 100.0 & 100.0 & \\
\hline
\end{tabular}

Dari tabel 1. diketahui bahwa laju metabolik responden terdapat laju metabolik ringan sebanyak 45 responden
$(65,2 \%)$, sedangkan laju metabolik sedang sebanyak 24 responden $(34,8 \%)$. 
Tabel 2. Distribusi Frekuensi Hasil Pengukuran Durasi Kerja Pada Pekerja Yang Bekerja Di Home Industry Pembuatan Sandal RW 04 Kelurahan Pamoyanan Kecamatan Bogor Selatan Kota Bogor Tahun 2019

\begin{tabular}{llr|r|r|r} 
& \multicolumn{2}{c}{ Frequency } & Percent & Valid Percent & Cumulative Percent \\
\hline Valid & 46 & 66.7 & 66.7 & 66.7 \\
\hline $50 \%-75 \%$ & 23 & 33.3 & 33.3 & 100.0 \\
\hline & & & & \\
\hline
\end{tabular}

Dari tabel 2. diketahui bahwa durasi

kerja dari 69 responden terdapat 46 responden durasi kerjanya $(75 \%-100 \%)$ melebihi dari 8 jam kerja sehari dan hanya istirahat 30 menit sebanyak $(66.7 \%)$, sedangkan durasi kerja $(50 \%-75 \%)$ bekerja 8 jam sehari dan istirahatnya 60 menit sebanyak 23 responden $(33.3 \%)$.

Tabel 3. Distribusi Frekuensi Hasil Pengukuran Jenis Pakaian Kerja Pada Pekerja Yang Bekerja Di Home Industry Pembuatan Sandal RW 04 Kelurahan Pamoyanan Kecamatan Bogor Selatan Kota Bogor Tahun 2019

\begin{tabular}{llr|rr|r} 
& Frequency & Percent & Valid Percent & $\begin{array}{c}\text { Cumulative } \\
\text { Percent }\end{array}$ \\
\hline Valid Pakaian Kerja Biasa & 69 & 100.0 & 100.0 & 100.0 \\
\hline
\end{tabular}

Dari tabel 3. diketahui bahwa jenis pakaian kerja seluruh responden menggukanan pakaian kerja biasa sebanyak 69 responden $(100 \%)$.

\section{Pembahasan}

Berdasarkan tabel 1. hasil penelitian bahwa aktivitas kerja pada pekerja yang bekerja di Home Industry sebagian besar termasuk golongan beban kerja ringan, aktifitas pekerjaan tergolong ringan adalah aktifitas melakukan pekerjaan dengan tangan dan lengan, lengan dan kaki. Pekerjaan pada pekerja di Home Industry RW 04 yaitu mengangkat sandal dalam karung lalu dipindahkan ke mobil, menarik sandal agar tersambung penjepitnya dan menjadi sendal yang bisa dipakai, menarik beban berat alat cetak untuk memotong sandal, mengumpulkan limbah sandal yang begitu banyak lalu di angkat ke dalam mobil untuk diolah kembali, bongkar muat bahan dasar sandal dari mobil. Hal ini mempengaruhi laju metabolik pekerja.

Menurut Suma'mur (2009) Produksi panas tubuh tergantung dari kegiatan fisik tubuh. Panas sebenarnya merupakan energi kinetik gerak molekul yang secara terus menerus dihasilkan dalam tubuh sebagai hasil samping metabolisme dan pertukaran panas diantara tubuh dan lingkungan sekitar. Penelitian ini sejalan dengan Amaliya (2018) menunjukan bahwa hasil laju metabolik ringan $(72,2 \%)$ lebih banyak ditemukan, disebabkan aktifitas pekerjaan tergolong sedang dan berat seperti mendorong perahu ketengah air, menarik jangkar, memperbaiki mesin kapal, membawa jaring kedalam kapal, bongkar muat es balok dan ikan.

Berdasarkan tabel 2. hasil penelitian bahwa responden yang bekerja melebihi 8 jam yaitu mereka yang bekerja mulai dari pukul 7 pagi hingga pukul 8/9 malam dan istirahat hanya 30 menit sedangkan responden yang bekerja 8 jam sehari yaitu mereka yang bekerja mulai pukul $7 / 8$ pagi hingga pukul $4 / 5$ sore dengan waktu istirahat 60 menit.

Menurut Alpaugh (1988) pakaian kerja merupakan alat pelindung diri yang sangat 
penting jika pekerja berada di daerah dengan suhu tinggi. Dengan media perantara, jumlah paparan panas ke kulit dapat dikurangi. Pekerjaan dengan paparan panas yang tinggi, sering kali bergantung kepada pantulan pakaian yang digunakan. Penelitian ini sejalan dengan Amaliya (2018) menunjukan bahwa hasil pakaian kerja lengan pendek $(60,0 \%)$ dan lengan panjang $(40,0 \%)$ kedua pakaian kerja tersebut masuk kategori pakaian kerja biasa disebabkan hasil dari kuesioner bahwa lebih banyak pakaian yang digunakan responden yaitu baju berbahan kaos dengan lengan pendek, bahan yang tidak menyerap kerigat, dan memakai celana dengan bahan tipis dan pendek.

Berdasarkan tabel 3. hasil penelitian bahwa dari 69 responden seluruh pekerja menggunakan pakaian kerja biasa yaitu baju kemeja, baju berbahan kaos dengan lengan

\section{Kesimpulan}

1. Hasil pengukuran iklim lingkungan kerja ISBB (Indeks Suhu Basah dan Bola) dengan menggunakan alat WBGT (Wet Bulb Globe Temperature) didapatkan hasil rata-rata yaitu $29,93{ }^{\circ} \mathrm{C}$ sedangkan pengukuran ISBB (Indeks Suhu Basah dan Bola) paling rendah $25,93{ }^{\circ} \mathrm{C}$ dan hasil ISBB (Indeks Suhu Basah dan Bola) paling tinggi sebesar $33,22^{\circ} \mathrm{C}$.

2. Hasil penelitian laju metabolik menggunakan lembar pengukuran didapatkan bahwa dari 69 pekerja mayoritas laju metaboliknya ringan pendek, berbahan kaos dengan lengan Panjang, berbahan kaos dengan lengan oblong dan memakai celana dengan bahan tipis panjang dan pendek. Jenis pakaian tersebut memiliki bobot untuk koreksi indeks WBGT. Hal ini tidak berpengaruh terhadap tekanan panas karena tidak ada penambahan nilai untuk hasil indeks WBGT.

Menurut Tarwaka dkk (2004) selama aktifitas pada lingkungan panas, tubuh secara otomatis akan memberikan reaksi untuk memelihara suatu kisaran panas lingkungan yang konstan, dengan menyeimbangkan antara panas yang diterima dari luar tubuh dengan kehilangan panas dari dalam tubuh. Penelitian ini sejalan dengan Wulandari, K (2016) menunjukan bahwa hasil durasi kerja keseluruhannya yaitu $75 \%$ - $100 \%$ disebabkan bekerja melebihi 8 jam sehari dan istirahat selama $1 \mathrm{jam}$

sebanyak (65.2\%).

3. Hasil penelitian durasi kerja menggunakan lembar pengukuran didapatkan bahwa dari 69 pekerja mayoritas pekerja durasi kerjanya melebihi 8 jam dan istirahat hanya 30 menit $(75-$ $100 \%)$ sebanyak (66.7\%).

4. Hasil penelitian jenis pakaian kerja menggunakan lembar pengukuran didapatkan bahwa 69 responden jenis pakaian kerjanya menggunakan pakaian kerja biasa sebesar $100 \%$. 


\section{Daftar Pustaka}

[1]. Hastono, P, S. 2016. Analisis Data Pada Bidang Kesehatan. PT RajaGrafindo Persada. Jakarta

[2]. ILO. 2016. Good Practices and Challenges Ni Promoting Decent Work Ni Construction and Infrastructure Projects. Ganeva: ILO

[3]. Kurniawidjaja, M. 2010. Teori Dan Aplikasi Kesehatan Kerja. Jakarta: Penerbit Universitas Indonesia.

[4]. Nurmianto E. 2003. Ergonomi: Konsep Dasar dan Aplikasinya. Surabaya: Guna widya.

[5]. Pemerintah Indonesia. 2011. Peraturan Menteri Tenaga Kerja dan Transmigrasi Nomor PER.13/Men/x/2011 Tahun 2011 Tentang Nilai Ambang Batas Faktor Fisika dan Faktor Kimia di
Tempat Kerja.

[6]. Soeripto M. 2008. Higiane Industri. Jakarta: Balai penerbit FK UI

[7]. Suma'mur, 2009. Higiene Perusahaan dan Kesehatan Kerja. Jakarta: PT. Toko Gunung Agung.

[8]. Sugiyono. 2010. Metode Penelitian Pendidikan Pendekatan Kuantitatif, Kualitatif, dan R\&D. Bandung: Alfabeta

[9]. Telan, A, B. 2012. Pengaruh Tekanan Panas Terhadap Perubahan Tekanan Darah Dan Denyut Nadi Pada Tenaga Kerja Industri Pandai Besi Di Desa Hadipolo Kecamatan Jekulo Kabupaten Kudus Jawa Tengah. Semarang: Universitas Diponegoro. 